\title{
A Multiplexed Diagnostic Platform for Point-of-Care Pathogen Detection
}

J. F. Regan, S. E. Letant, K. L. Adams, R. C. Mahnke, N. T. Nguyen, J. M. Dzenitis, B. J. Hindson, D. R. Hadley, T. J. Makarewicz, B. D. Henderer, J. W. Breneman, L. F. Tammero, J. I. Ortiz, R. W. Derlet, S. Cohen, W. W. Colston, M. T. McBride, J. M. Birch

February 4, 2008 
This document was prepared as an account of work sponsored by an agency of the United States government. Neither the United States government nor Lawrence Livermore National Security, LLC, nor any of their employees makes any warranty, expressed or implied, or assumes any legal liability or responsibility for the accuracy, completeness, or usefulness of any information, apparatus, product, or process disclosed, or represents that its use would not infringe privately owned rights. Reference herein to any specific commercial product, process, or service by trade name, trademark, manufacturer, or otherwise does not necessarily constitute or imply its endorsement, recommendation, or favoring by the United States government or Lawrence Livermore National Security, LLC. The views and opinions of authors expressed herein do not necessarily state or reflect those of the United States government or Lawrence Livermore National Security, LLC, and shall not be used for advertising or product endorsement purposes.

This work performed under the auspices of the U.S. Department of Energy by Lawrence Livermore National Laboratory under Contract DE-AC52-07NA27344. 


\title{
FY07 LDRD Final Report A Multiplexed Diagnostic Platform for Point-of-Care Pathogen Detection 05-ERD-049 John Regan
}

\begin{abstract}
We developed an automated point-of-care diagnostic instrument that is capable of analyzing nasal swab samples for the presence of respiratory diseases. This robust instrument, called FluIDx, performs autonomous multiplexed RT-PCR reactions that are analyzed by microsphere xMAP technology. We evaluated the performance of FluIDx, in comparison rapid tests specific for influenza and respiratory syncytial virus, in a clinical study performed at the UC Davis Medical Center. The clinical study included samples positive for RSV $(n=71)$, influenza A $(n=16)$, influenza B $(n=4)$, adenovirus $(\mathrm{n}=5)$, parainfluenza virus $(\mathrm{n}=2)$, and 44 negative samples, according to a composite reference method. FluIDx and the rapid tests detected $85.9 \%$ and $62.0 \%$ of the RSV positive samples, respectively. Similar sensitivities were recorded for the influenza B samples; whereas the influenza A samples were poorly detected, likely due to the utilization of an influenza A signature that did not accurately match currently circulating influenza A strains. Data for all pathogens were compiled and indicate that FluIDx is more sensitive than the rapid tests, detecting $74.2 \%$ (95\% C.I. of $64.7-81.9 \%)$ of the positive samples in comparison to $53.6 \%(95 \%$ C.I. of $43.7-63.2 \%)$ for the rapid tests. The higher sensitivity of FluIDx was partially offset by a lower specificity, $77.3 \%$ versus $100.0 \%$. Overall, these data suggest automated flow-through PCR-based instruments that perform multiplexed assays can successfully screen clinical samples for infectious diseases.
\end{abstract}

\section{Introduction/Background}

This project was funded by the LDRD committee to address the lack of rapid and accurate diagnostic tools at our healthcare facilities. The diagnostic tools currently available to point-of-care physicians are limited to immuno-assay based rapid test strips, which are only approximately $70 \%$ sensitive and screen for only one or two pathogens at a time. RT-PCR assays are approximately 100-fold more sensitive than immuno-assays and can be multiplexed to detect many pathogens in one assay. Currently, RT-PCR analysis requires a skilled technician working in a fully equipped clinical microbiology laboratory. The purpose of this LDRD project was to develop an automated instrument that would essentially replace the requirement of having a skilled technician perform manual RT-PCR assays to diagnosis a patient's sample. During the first two years of this LDRD project, we developed the first-ever bead-based multiplex instrument that is fully automated. The last year of the LDRD project focused on the evaluation of this new instrument against the immuno-assay tests. The positive data generated during the clinical trial demonstrates the proof-of-principle behind automating these types of assays and will hopefully lay the groundwork to bringing bead-based multiplex assays out of the laboratory and to the point-of-care where they will offer a better diagnostic alternative than immuno-assay tests. The arrival of this type of technology to the clinic will change 
the manner in which care is delivered, including decisions surrounding prescribing antimicrobial drugs and admitting or discharging patients.

\section{Results}

Detailed descriptions of both the automated instrument and the clinical study are provided in the attached manuscripts, which at the time of writing this report, are being submitted for publication to the Journal of Clinical Microbiology. The first manuscript details the construction and operation of the instrument, and an analytical study that evaluated the ability of the instrument to reliably analyze samples in a reproducible manner. The second paper details the results of a clinical study using FluIDx and rapid tests to diagnose patient samples collected at the UC Davis Medical Center. The clinical study involved screening 141 nasal swab samples for respiratory viruses. Analysis of these data indicates that FluIDx is more sensitive, but less specific than the rapid tests. FluIDx has the added advantage of being able to screen for multiple pathogens at a time, thereby reducing overall cost and labor associated with determining the diagnosis of a sample.

\section{Exit Plan}

LLNL's Industrial Partnership Office has licensed FluIDx intellectual property to Tassajara Technologies and is currently negotiating a CRADA agreement to facilitate the commercialization of this technology in the private sector. 